\title{
Requirements for Hypermedia Development Methods: A Survey of Outstanding Methods
}

\author{
Susana Montero, Paloma Díaz, and Ignacio Aedo \\ Laboratorio DEI. Dpto. de Informática, Universidad Carlos III de Madrid \\ Avda. de la Universidad 30. 28911 Leganés, Spain \\ smontero@inf.uc3m.es \\ pdp@inf .uc3m.es \\ aedo@ia.uc3m.es \\ http://www.dei.inf.uc3m.es
}

\begin{abstract}
The aim of this paper is to present a framework of requirements to survey design methods for hypermedia systems. Such requirements are taken from software engineering as well as from hypermedia engineering fields. Finally, these requirements are applied to a set of outstanding design methods in order to identify both their good qualities and their lacks.
\end{abstract}

\section{Introduction}

Hypermedia systems, and specially web applications, have been extremely and ungently demanded in different areas. The rush to develop applications has led most developers to skip the conceptual design phase and directly go to the implementation stage, producing applications of poor quality, usability and maintainability.

Such tools do not pay attention to intrinsic features of hypermedia systems such as sophisticated navigational structures, interactive behaviours and multimedia compositions. Moreover, another feature which should be taken into account is security, since hypermedia applications are accessed by different users with different purposes [4].

Many research and development groups have proposed a series of methods which are used as a guideline during the design process.

In this paper, we analyse some of these methods such as HDM, RMM, OOHDM, WSDM, Autoweb, WebML and OO-H method. This survey starts defining a framework of requirements to cover the modeling space of design methods for hypermedia systems from the literature and the experience of our group in the design of this kind of systems [4,5]. On the basis of this framework, the methods previously mentioned have been evaluated to assess their modeling capabilities. This survey can be also useful for novice hypermedia developers to choose the most suitable method according to their needs. 


\section{A Framework for Hypermedia System Design Methods}

To analyse different design methods, it is necessary to establish a framework that determines what elements, activities and design views must be taken into account by a method. In our case, this framework is determined by a set of requirements gathered both from the software and hypermedia engineering fields.

\subsection{Requirements Derived from Software Engineering}

The experience gained in years of research in the software field about modeling techniques, methods and methodologies can help to improve hypermedia development [11]. We borrow some features from this area, but do not consider issues such as project planning or project management since our survey will be centred on the design of hypermedia systems. According to $[1,15]$, any design software method must:

- Describe a formal process to guide the development of a software application.

- Contain a model to describe the real world and transfer it to a physical system.

- Provide the designer with products to specify functional, non-functional and usability requirements.

- Include validation rules for each design product.

- Maintain relations of integrity among the different design products.

- Allow design reuse.

- Count on software support tools to help in the development process.

\subsection{Requirements Derived from Hypermedia Technology}

It is necessary to stress the following requirements took from hypermedia engineering [3,13].

- Allow to describe the problem domain in terms of hypermedia components: nodes, contents, links and anchors.

- Provide tasks to model the navigation structure, both the links structure and the navigation tools (visual maps, active indexes, guided tours, marks, footprints and backtracking mechanisms).

- Organize and harmonize multimedia contents.

- Model the different types of users.

- Provide conceptual tools to formalize security policies.

- Allow to describe the interactive behaviour of hypermedia systems.

- Allow a bottom-up design.

- Make possible the evaluation of the system utility. 


\section{Methods under Consideration}

It is difficult to find a hypermedia design method that is appropriated for the development of any hypermedia system due to rapid change in this technology and the mix of different techniques and fields (database, object oriented, hypermedia, web, ...) which have to be applied. However, the methods here presented are a proof of the concern about covering process modeling of hypermedia systems. Those methods are HDM [8], RMM [10], OOHDM [14], WSDM [6], Autoweb [7], WebML [2], (OO-H) method [9].

Table 1 presents the summary of analysis of these methods performed using the framework. The left part enumerates the software and hypermedia requirements and on the right side their rate of performance is shown for each method. Three kinds of notations have been used: $\mathrm{C}$, if the method fulfills the whole of requirement; $\mathrm{P}$, if the method allows it partially; and $\mathrm{N}$ when the requirement are not dealt by the method.

Table 1. Comparison between requirements and methods

\begin{tabular}{|c|c|c|c|c|c|c|c|}
\hline Requirements for design methods of hypermedia system & $\mathbf{H}$ & $\mathbf{T} \mathbf{R}$ & 100 & W & Aut & 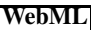 & 00 \\
\hline process modeling & $\mathrm{P}$ & $\mathrm{C}$ & $\mathrm{C}$ & $\mathrm{C}$ & $\mathrm{C}$ & $\mathrm{C}$ & $\mathrm{P}$ \\
\hline based on a model & $\mathrm{C}$ & $\mathrm{C}$ & $\mathrm{P}$ & $\mathrm{P}$ & $\mathrm{C}$ & $\mathrm{P}$ & $\mathrm{P}$ \\
\hline functional, no-functional and usability requirements & $\mathrm{P}$ & $\mathrm{P}$ & $\mathrm{P}$ & $\mathrm{P}$ & $\mathrm{P}$ & $\mathrm{P}$ & $\mathrm{P}$ \\
\hline validation rules for each product & $\mathrm{N}$ & $\mathrm{N}$ & $\mathrm{N}$ & $\mathrm{N}$ & $\mathrm{N}$ & $\mathrm{P}$ & $\mathrm{N}$ \\
\hline integrity relationships among phases & $\mathrm{N}$ & $\mathrm{N}$ & $\mathrm{N}$ & $\mathrm{N}$ & $\mathrm{N}$ & $\mathrm{N}$ & $\mathrm{N}$ \\
\hline design reuse & $\mathrm{C}$ & $\mathrm{N}$ & $\mathrm{C}$ & $\mathrm{N}$ & $\mathrm{N}$ & $\mathrm{P}$ & $\mathrm{C}$ \\
\hline software support tools & $\mathrm{C}$ & $\mathrm{P}$ & $\mathrm{P}$ & $\mathrm{N}$ & $\mathrm{C}$ & $\mathrm{C}$ & $\mathrm{C}$ \\
\hline hypermedia components & $\mathrm{C}$ & $\mathrm{C}$ & $\mathrm{C}$ & $\mathrm{P}$ & $\mathrm{C}$ & $\mathrm{C}$ & $\mathrm{C}$ \\
\hline navigation structure & $\mathrm{C}$ & $\mathrm{C}$ & $\mathrm{C}$ & $\mathrm{P}$ & $\mathrm{C}$ & $\mathrm{C}$ & $\mathrm{C}$ \\
\hline organization and harmonization of multimedia contents & $\mathrm{C}$ & $\mathrm{P}$ & $\mathrm{P}$ & $\mathrm{N}$ & $\mathrm{P}$ & $\mathrm{P}$ & $\mathrm{N}$ \\
\hline user modeling & $\mathrm{N}$ & $\mathrm{N}$ & $\mathrm{C}$ & $\mathrm{C}$ & $\mathrm{N}$ & $\mathrm{C}$ & $\mathrm{N}$ \\
\hline formalization of security policies & $\mathrm{N}$ & $\mathrm{N}$ & $\mathrm{N}$ & $\mathrm{N}$ & $\mathrm{N}$ & $\mathrm{N}$ & $\mathrm{N}$ \\
\hline description of interactive behaviour & $\mathrm{C}$ & $\mathrm{N}$ & $\mathrm{C}$ & $\mathrm{N}$ & $\mathrm{N}$ & $\mathrm{C}$ & $\mathrm{C}$ \\
\hline bottom-up design & $\mathrm{C}$ & $\mathrm{C}$ & $\mathrm{N}$ & $\mathrm{N}$ & $\mathrm{N}$ & $\mathrm{N}$ & $\mathrm{N}$ \\
\hline evaluation of system utility & $\mathrm{C}$ & $\mathrm{C}$ & $\mathrm{N}$ & $\mathrm{N}$ & $\mathrm{N}$ & $\mathrm{N}$ & $\mathrm{N}$ \\
\hline
\end{tabular}

From this table, the following conclusions can be observed. On the one hand, all of these methods are making an effort to establish the steps and techniques to get a scalable, maintainable and usable application. They contain a model to represent the essence of the design using hypermedia components and navigation structures in a automatic way. Moreover, methods mention the interactive behaviour, although they do not make clear how to specify or use it.

Some weak points are also revealed during this survey including:

- No-functional and usability characteristics. These kinds of characteristics could improve the quality and efficiency of the system.

- Validation and integrity rules. This kind of rules help determine the correctness and the completeness of design and the integrity of the designed elements.

- Design reuse. Interface and structure patterns, as well as design components allow us to reuse designers' experience. 
- Content modeling. It allows us to represent different data views in addition to handling aesthetic aspects with synchronization and alignment of contents.

- User modeling. This modeling allows us to handle system adaptability in a conceptual way.

- Security modeling. This characteristic allows us to define security constraints and apply access control mechanisms to different system users.

- Bottom-up design. This design way together with a top-down design allow a better feedback among stages [12].

- Evaluation stage. This stage could help improve the utility and usability of the application and make possible a development more incremental and iterative.

\section{Conclusions}

This work is a glance into process modeling of hypermedia systems in order to observe and measure the current state of this area. Some ideas can be taken from it to identify new research directions. HDM is the method that covers more requirements, in spite of being the oldest one. So, designers should have it as a basis for their researches. Moreover, both hypermedia and web methods should put more stress on characteristics such as multimedia compositions, user adaptability, security politicies and evaluation mechanisms which are more particular of hypermedia systems.

Finally, the requirements here presented can be used as a framework to compare hypermedia methods.

\section{Acknowledgements}

This work is supported by "Dirección General de Investigación del Ministerio de Ciencia y Tecnología" (TIC2000-0402)."

\section{References}

1. Avison, D.E. and Fitzgerald, G. Information systems development: techniques and tools. Blackwell Scientific Publications, Oxford, 1995. 748

2. Ceri, S., Fraternali, P. and Bongio, A. Web modeling language (WebML): a modeling language for designing web sites. WWW9 / Computer Networks, 33(1-6):137157, 2000. 749

3. Díaz, P., Aedo, I. and Montero, S. Ariadne, a development method for hypermedia. In proceedings of Dexa 2001, volume 2113 of Lecture Notes in Computer Science, pages $764-774,2001.748$

4. Díaz, P., Aedo, I. and Panetsos, F. Modelling security policies in hypermedia and web-based applications. In Web Engineering: Managing diversity and complexity of web application development, volume 2016, pages 90-104. Springer, 2001. 747 
5. Díaz, P., Aedo, I. and Panetsos, F. Modelling the dynamic behaviour of hypermedia applications. IEEE Transactions on Software Engineering, 27(6):550-572, June 2001. 747

6. De Troyer, O. and Leune, C. WSDM: a user centered design method for web sites. In Proceedings of the 7th International World-Wide Web Conference, 1998. 749

7. Fraternali, P. and Paolini, P. Model-driven development of web applications: the autoweb system. ACM Transactions on Office Information Systems, 18(4):323282, 2000. 749

8. Garzotto, F., Paolini, P. and Schwbe, D. HDM- a model-based approach to hypertext application design. ACM Transactions on Information Systems, 11(1):1-26, 1993. 749

9. Gómez, J. Cachero, C. and Pastor, O. Conceptual modeling of device-independent web applications. IEEE MultiMedia, 8(2):26-39, 2001. 749

10. Isakowitz, T. and Kamis, A. and Koufaris, M. The extended RMM methodology for web publishing. Technical Report IS98 -18, Center for Research on Information Systems, 1998. 749

11. Lowe, D. and Webby, R. The impact process modelling project work in progress. In 1st International Workshop on Hypermedia Development Held in conjunction with Hypertext'98, Pittsburgh, PA, USA, June 20-24 1998. 748

12. Nanard, J. and Nanard, M. Hypertext design environments and the hypertext design process. Comm. of the ACM, 38(8):49-56, 1995. 750

13. Retschitzegger, W. and Schwinger, W. Towards modeling of dataweb applications - a requirements' perspective. In Proc. of the Americas Conferenc on Information Systems (AMCIS) Long Beach California, volume 1, 2000. 748

14. Schwabe, D. and Rossi, G. An object oriented approach to web-based application design. Theory and practice of object systems, 4(4):207-225, 1998. 749

15. Sommerville, I. and Sawyer, P. Requirements engineering: a good practice guide. Wiley, Chichester, 1997. 748 